\title{
A study of the thermal properties of an alternative straw-containing building material
}

\author{
Penka Zlateva ${ }^{1, *}$, Krastin Yordanov $^{1}$, and Rositsa Petkova-Slipets ${ }^{2}$ \\ ${ }^{1}$ TU Varna, Department of Thermal Engineering,1 Studentska Str., 9010 Varna, Bulgaria \\ ${ }^{2}$ VFU “Chernorizets Hrabar", Department of Civil Engineering, Resort Chaika, 9007 Varna, Bulgaria
}

\begin{abstract}
Thermal comfort in buildings is usually achieved through sustainable materials obtained from natural sources, which justifies their use for developing building mixtures. Many natural materials were used as early as in ancient times to build homes that are warm in winter and cool in summer: a mixture of straw, clay and sand is an example of such a material. The objective of this article is to evaluate the effect of a mixture of clay, sand and straw on thermal comfort. For the purposes of this study, several types of sample plates were made from clay and sand mixture by adding different amounts of straw. The experiments were carried out and the thermal conductivity coefficient was determined using the method of infinite flat layer. The results indicate that the combination of different amounts of straw can be considered as good reinforcement of the sand and clay matrix and is characterized by a low thermal conductivity. Furthermore, 3D modelling was performed using Finite Element Analysis (FEA) software and a predictive model of the thermal behaviour of the samples from the different mixtures was developed. The thermal field distribution and the thermal conductivity coefficient thus determined were compared with the experimental data and showed consistency.
\end{abstract}

\section{Introduction}

Since the beginning of the 21st century, the problem of energy renovation of existing building stock and construction of low-energy new buildings is particularly relevant. The main reason for this is global warming and the resulting adverse climate change. Despite the introduction of new technologies and the development of modern and innovative building materials, humanity is returning to its natural habitat. New trends and standards for sustainable architecture and construction are being imposed. Houses made from alternative building materials such as straw, clay and adobe, in which people once lived, are becoming increasingly attractive. Their main advantage is that they are natural materials that have a low carbon footprint [1].

Some of the requirements that modern products designed for transport, industrial and domestic applications must meet are environmental friendliness, cost effectiveness and energy efficiency. The energy efficiency parameters are of particular importance as they directly determine the thermal and hygienic comfort in the building or facility; the

*Corresponding author: pzlateva@tu-varna.bg 
possibilities and terms for return on investments; the competitiveness of the material or article [2-3].

Alternative building materials based on natural materials satisfy all the requirements mentioned above: - they are low-cost as they are derived from natural resources and their use does not involve thermal or mechanical processing; - they are environmentally friendly materials with a zero carbon footprint; - they create a favourable microclimate in the inhabited buildings [4-5].

The study of the thermal parameters of alternative building materials continues to be a topical issue, as there are many factors that affect their actual thermal properties composition, method of forming and acquiring the final structure, temperature and humidity operating conditions, etc. This necessitates experimental studies of the thermo-physical parameters of the various moulded mixtures of alternative building materials and predicting their thermal behaviour, which can be achieved through simulation modelling.

\section{Materials and methods}

The present work presents the findings of the study of the thermo-physical parameters of alternative building materials, which are measured experimentally and determined. The samples from a mixture of clay and sand with different amounts of straw added are plateshaped.

A test stand employing the method of infinite flat plate is used.

In addition, using Autodesk Inventor Nastran 2020 software, simulation 3D models are developed in order to visualize their thermal behaviour. This allows the evaluation of the actual behaviour of the matrix of clay and sand as well as of the different straw proportions. The simulation model aims to adequately reproduce the results of experimental studies and to determine with sufficient accuracy the temperature distribution in the real objects represented by the models.

\subsection{Experimental materials}

For the purposes of the present study, four samples were tested (Fig. 1), with their composition indicated in Table 1.

Table 1. Sample composition

\begin{tabular}{|c|c|c|c|}
\hline $\begin{array}{c}\text { Sample } \\
\text { Type }\end{array}$ & \multicolumn{3}{|c|}{ Materials } \\
\hline 1 & clay (grey marl) & sand & 0 g straw \\
\hline 2 & clay (grey marl) & sand & 68 g straw \\
\hline 3 & clay (grey marl) & sand & 102 g straw \\
\hline 4 & clay (grey marl) & sand & 136 g straw \\
\hline
\end{tabular}

The samples were prepared as follows: Unbaked clay was dissolved in water to a plastic state and sand was added, the ratio being 1: 2 . With samples 2, 3 and 4, chopped straw was added in the proportions presented in Table 1. The water-clay ratio for all types of sample is 0,5 . The composition was stirred until a homogeneous mixture was obtained, which was then poured into wooden moulds of a square cross section, with a length of the side of 0.24 $\mathrm{m}$. The samples are dried at room temperature. Sandpaper was used to smooth all surface irregularities as well as possible in order to prevent the occurrence of errors in the test stand measurements [6]. 


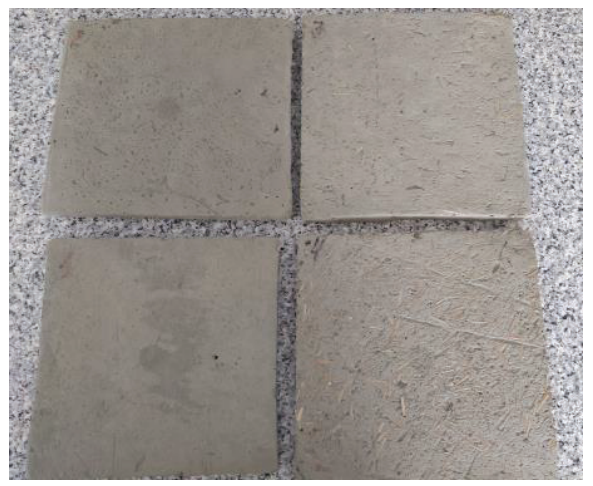

Fig. 1. General view of the studied samples

The thickness of the plates $(\delta)$ was measured with a dial indicator so that the density of the tested composite structures $(\rho)$ be accurately determined and their thermo-physical characteristics be evaluated, particularly their specific heat capacity. The results are presented in Table 2 below.

Table 2. Physical data for test samples

\begin{tabular}{|c|c|c|c|}
\hline Sample & $\boldsymbol{\delta}$ & $\mathbf{~ m}$ & $\boldsymbol{\rho}$ \\
\hline & $\mathbf{m}$ & $\mathrm{kg}$ & $\mathbf{k g} / \mathbf{m}^{\mathbf{3}}$ \\
\hline 1 & 0,0240 & 2,765 & 2000 \\
\hline 2 & 0,0241 & 2,606 & 1877 \\
\hline 3 & 0,0245 & 2,451 & 1737 \\
\hline 4 & 0,0247 & 2,394 & 1683 \\
\hline
\end{tabular}

\subsection{Experimental test method}

The experimental research employs a test stand based on the method of infinite flat plate, Fig.2. The principle of operation of the stand is as follows - the sample is placed between two flat plates at different temperatures. The higher-temperature plate (the hot plate) is kept at a constant temperature by supplying electricity. The temperature of the colder plate (the cold plate) is maintained constant by removing heat through water cooling. The hot plate is covered by a protective plate at a constant temperature, which prevents heat loss upwards and sideways. Thus, in a quasi-stationary mode the electric power supplied to the hot plate is proportional to the heat flow to the sample.

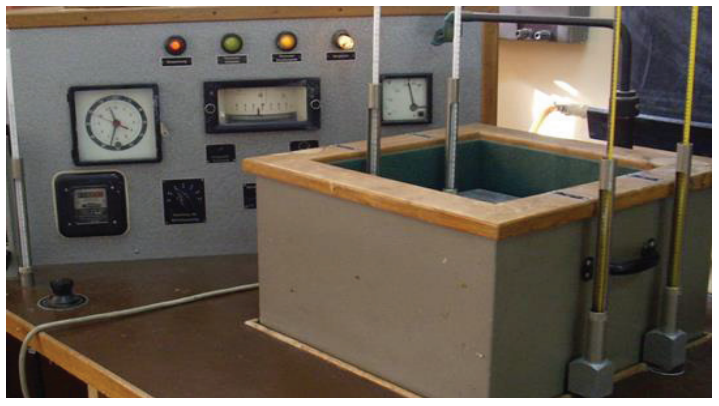

Fig. 2. Test stand based on the method of infinite flat plate 


\subsection{Simulation modelling of the samples studied}

The simulation modelling is based on the data obtained from the experimental studies of the samples discussed above. In the technology of thermal processes, solving problems of this nature requires the application of an algorithm. For the purposes of the present study, the following algorithm is applied:

1. Creating geometry using Autodesk Inventor Professional 2020 (Fig. 3);

2. Specifying the materials; (Table 3);

3. Transition to Autodesk Inventor Nastran 2020;

4. Selection of stationary thermal analysis;

5. "Discretisation" - splitting the image into finite elements;

6. Specifying the boundary conditions;

7. Specifying the number of iterations;

8. Solving the problem;

9. Results;

10. Analysis of the results.

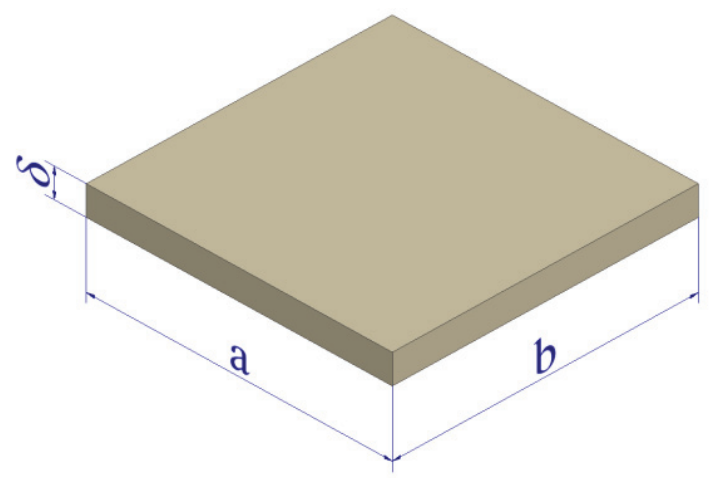

Fig. 3. Geometric model of the plate

Table 3 presents the properties of the materials in the modelled plate. They were determined by experimental studies and serve as input data for the simulation modelling [78].

Table 3. Dimensions and thermo-physical properties of the modelled plate

\begin{tabular}{|c|c|c|c|c|c|c|}
\hline \multirow{3}{*}{ Plate Type } & \multicolumn{3}{|c|}{ Dimensions } & \multicolumn{3}{|c|}{ Physical Properties } \\
\hline & $\mathbf{a}$ & b & $\delta$ & $\rho$ & $c_{p}$ & $\mathbf{k}$ \\
\hline & $\mathbf{m}$ & m & $\mathbf{m}$ & $\mathrm{kg} / \mathrm{m}^{3}$ & J/(kg.K) & $\mathrm{W} /(\mathbf{m} . \mathbf{K})$ \\
\hline 1 & \multirow{4}{*}{0,24} & \multirow{4}{*}{0,24} & 0,0240 & 2000 & 456,78 & 0,562 \\
\hline 2 & & & 0,0241 & 1877 & 721,45 & 0,436 \\
\hline 3 & & & 0,0245 & 1737 & 907,21 & 0,254 \\
\hline 4 & & & 0,0247 & 1683 & 968,83 & 0,228 \\
\hline
\end{tabular}

The simulation modelling of the thermal processes in the plates was performed with the software product "Autodesk Inventor Nastran 2020", which is suitable for the purposes of the research. Stationary thermal analysis was conducted.

Materials with the thermo-physical parameters of the plates presented in Table 3 were added to Autodesk Inventor Professional 2020 library.

Fig. 4 illustrates the boundary conditions specified. 


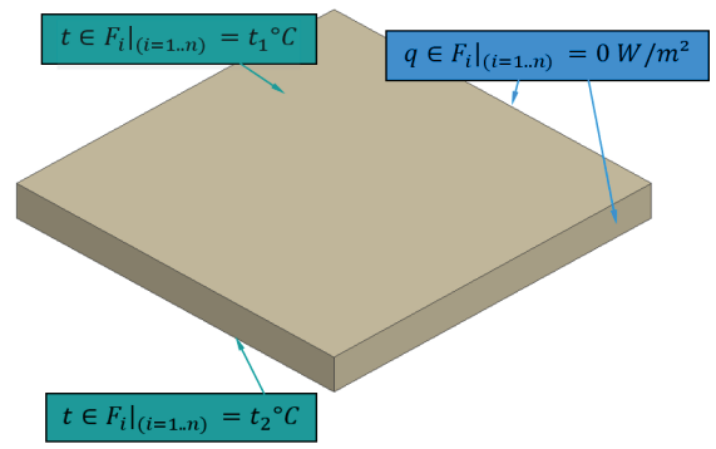

Fig. 4. Plate surface boundary conditions specified

The mathematical modelling of the stationary thermal analysis was performed by the differential equation (1) [9]:

$$
\frac{\partial}{\partial x}\left[k \frac{\partial T}{\partial x}\right]+\frac{\partial}{\partial y}\left[k \frac{\partial T}{\partial y}\right]+\frac{\partial}{\partial z}\left[k \frac{\partial T}{\partial z}\right]=0
$$

The developed algorithm for 3D modelling of thermal processes in various thermal insulation materials and coatings allows the use of software products that can predict the processes, varying the input parameters.

\section{Results and Discussion}

\subsection{From the experimental research}

Taking into account the tabular values of the thermal conductivity coefficients of the source materials used for the tested samples (dry and wet clay $\mathrm{k}^{\text {table }}{ }_{\text {marl }}=0,15 \div 1,8 \mathrm{~W} /(\mathrm{m} . \mathrm{K}$ ); sand with $10 \%$ humidity $\mathrm{k}^{\text {table }}{ }_{\text {sand }}=0,97 \mathrm{~W} /(\mathrm{m} . \mathrm{K})$; straw $\mathrm{k}^{\text {table }}{ }_{\text {straw }}=0,048 \mathrm{~W} /(\mathrm{m} . \mathrm{K})$, the samples were found to have a coefficient of thermal conductivity which is within the range of the measurement device [10].

In order to check the accuracy of the measurement of the device, a "zero" experiment was performed on a sample of glass, which has a tabular coefficient of thermal conductivity $\mathrm{k}_{\text {table }}^{\text {glass }}=1,15 \mathrm{~W} /(\mathrm{m} \cdot \mathrm{K})$. The value of the measured thermal conductivity of the glass sample was $\mathrm{k}_{\text {glass }}=1,115 \mathrm{~W} /(\mathrm{m} . \mathrm{K})$. The experimentally obtained value for the thermal conductivity of the glass sample $\mathrm{k}_{\text {glass }}$ differs from the tabular value by $3 \%$, which verifies the accuracy of the measurements [11].

The measurements of the samples tested were performed under the same conditions and the results are presented in Table 4.

Table 4. Experimental data for the samples tested

\begin{tabular}{|c|c|c|c|c|c|}
\hline Sample & $\begin{array}{c}\text { Average power } \\
\text { supplied }\end{array}$ & $\begin{array}{c}\text { Heat flux } \\
\text { density }\end{array}$ & $\begin{array}{c}\text { Average } \\
\text { temperature } \\
\text { difference }\end{array}$ & $\begin{array}{c}\text { Average air } \\
\text { temperature }\end{array}$ & $\mathrm{k}$ \\
\hline & $\mathrm{W}$ & $\mathrm{kcal} /\left(\mathrm{m}^{2} \cdot \mathrm{h}\right)$ & ${ }^{\circ} \mathrm{C}$ & ${ }^{\circ} \mathrm{C}$ & $\mathrm{W} /(\mathrm{m} . \mathrm{K})$ \\
\hline 1 & 36,8 & 251,307 & 11,45 & 26 & $\mathbf{0 , 5 6 2}$ \\
\hline 2 & 30 & 141,75 & 8,608 & 25,133 & $\mathbf{0 , 4 3 6}$ \\
\hline 3 & 16,8 & 79,38 & 9,075 & 26,533 & $\mathbf{0 , 2 5 4}$ \\
\hline 4 & 15,6 & 73,71 & 9,425 & 26,35 & $\mathbf{0 , 2 2 8}$ \\
\hline
\end{tabular}


The experimental data obtained provide for drawing the conclusion that in terms of insulating properties, the mixture of clay and sand is superior to some conventional building materials such as ceramic bricks, plain and aerated concrete, etc. In addition, with increasing the amount of straw in the studied building mixture, the coefficient of thermal conductivity decreases, i.e. samples containing a larger proportion of straw have better thermal insulation properties.

\subsection{From the simulation modelling}

The results of the simulation modelling are illustrated in Fig. 5. The boundary conditions, the results of the experiment, the analysis and the calculation error are presented in Table 5.

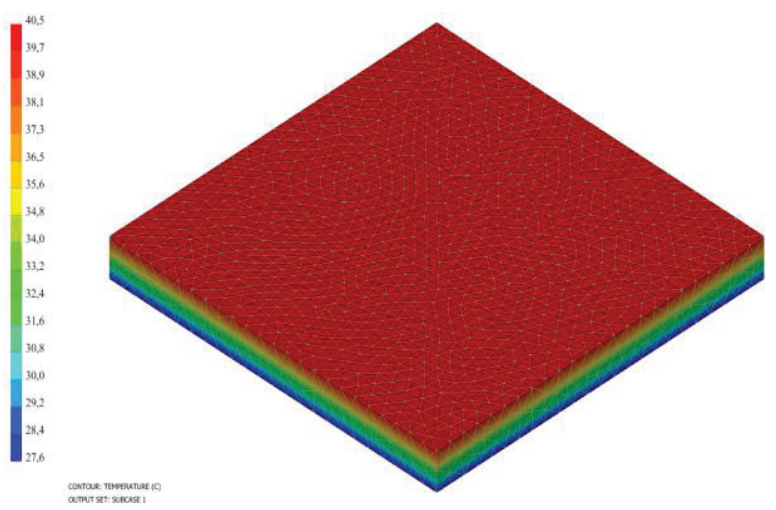

Fig. 5. Temperature distribution along the thickness of the plate thickness

Table 5. Boundary conditions, results of the experiment, analysis and calculation error

\begin{tabular}{|c|c|c|c|c|c|}
\hline \multirow{3}{*}{$\begin{array}{c}\text { Plate } \\
\text { Type }\end{array}$} & \multicolumn{2}{|c|}{ Boundary conditions } & Experiment & Analysis & \multirow{2}{*}{ Error } \\
\cline { 2 - 5 } & $\mathbf{t}_{\mathbf{1}}$ & $\mathbf{t}_{\mathbf{2}}$ & $\mathbf{q}_{\mathbf{e}}$ & $\mathbf{q}_{\mathbf{a}}$ & \\
\hline & ${ }^{\circ} \mathbf{C}$ & ${ }^{\circ} \mathbf{C}$ & $\mathbf{W} / \mathbf{m}^{\mathbf{2}}$ & $\mathbf{W} / \mathbf{m}^{\mathbf{2}}$ & $\mathbf{\%}$ \\
\hline $\mathbf{1}$ & 40,5 & 27,6 & 292,3 & 301,8 & 3,3 \\
\hline $\mathbf{2}$ & 34,6 & 25,9 & 164,9 & 157,6 & 4,4 \\
\hline $\mathbf{3}$ & 35,5 & 26,4 & 92,3 & 94,3 & 2,2 \\
\hline $\mathbf{4}$ & 35,7 & 26,2 & 84,2 & 87,7 & 4,2 \\
\hline
\end{tabular}

$\mathrm{t}_{1}$ - average temperature of the hot plate;

$t_{2}$ - average temperature of the cold plate;

$\mathrm{q}_{\mathrm{e}}$ - experimental heat flux;

$\mathrm{q}_{\mathrm{a}}$ - heat flux as per analysis;

The comparative analysis of the simulation modelling of the tested samples (Fig. 5 and Table 5) shows good repeatability and adequacy of the obtained results for the tested samples with a matrix of clay and sand and straw additives. The application of numerical methods and software products for simulation analysis is a step forward in solving problems of this nature. 


\section{Conclusions}

The following conclusions can be based on the above experiments and the simulation modelling results obtained for building mixtures of clay, sand and straw added:

1. In terms of insulating properties, the mixture of clay and sand is superior to some conventional building materials. The result obtained for the value of the thermal conductivity of the clay and sand sample is $\mathrm{k}_{1}=0,562 \mathrm{~W} /(\mathrm{m} \cdot \mathrm{K})$.

2. Depending on the amount of straw added to the clay-sand mixture, the results obtained for the value of the thermal conductivity of the samples with the lowest straw content is $\mathrm{k}_{2}=0,436 \mathrm{~W} /(\mathrm{m} . \mathrm{K})$ and with the highest e $\mathrm{k}_{4}=0,228 \mathrm{~W} /(\mathrm{m} . \mathrm{K})$. It was found that with increasing the amount of straw, the thermal conductivity coefficient decreases, i.e. the material acquires better insulating properties.

3. The simulation modelling of stationary thermal conductivity in the studied plates with a matrix of clay and sand and straw additives through the mathematical model adequately reproduces the thermal processes taking place in them and shows good repeatability of the results obtained.

The above conclusions about the thermal parameters of the studied building mixtures, and particularly the coefficient of thermal conductivity determined by experimental studies, as well as the adequacy of the simulation model provide grounds for confirming the possibilities for appropriate applications of the studied alternative building materials to improve thermal comfort and increase energy efficiency in buildings.

The investigations in that paper have been implemented with the financial support of National Programme "Young scientist and postdoctoral students", funded by Bulgarian Ministry of Education.

\section{References}

1. S. Roaf, M. Fuentes, S. Thomas, Ecohouse, A design guide (Third ed., Elsevier Ltd, 2007)

2. N. Penkova, K. Krumov, I. Kassabov, L. Zashkova, Eng. Tr. Gl. in Arch. and Str. Eng., 373 (2016)

3. J. Cha, J. Seo, S. Kim, J Therm Anal Calorim 109, 1 (2012)

4. V. Gandova, S. Tasheva, M. Dimitrova, Oxid. Commun. 43, 2, (2020)

5. Z. Kolev, S. Kadirova, TE-RE-RD, E3S Web of Conf. 180, 01009 (2020)

6. V. Bohac, M. Gustavsson, L. Kubicar, V. Vretenar, Meet. Thermoph. Soc. Conf. Proc. (2003)

7. F. Kreith, R. M. Manglik, M. S. Bohn, Principles of Heat Transfer (7th Ed., Cengage Learning, 2012)

8. M. Favre-Marinet, S. Tardu, Convective Heat Transfer: Solved Problems, (John Wilely and Sons, 2013)

9. W. S. Janna, Engineering Heat Transfer (Third Edition, Taylor \& Francis, 2009)

10. P. Ngohe-Ekam, P. Meukam, G. Menguy, P. Girard, Constr. Build. Mater. 20 (2006)

11. P. Zlateva, R. Petkova-Slipets, Ac. Tech. Corv. - Bull. Eng., 8 (2015) 